\title{
PREVENTION OF ARTHROPOD-VECTOR OF INFECTIOUS DISEASES BY INSECT REPELLENTS AND OTHER MEASURES
}

\author{
By \\ TOSSON A. MORSY ${ }^{*}$, AYMAN T. A. MORSY ${ }^{2}$ and EMAN E. ABDEL-FADIL ${ }^{3}$ \\ Faculty of Medicine, Ain Shams University, Cairo $11566^{1}$, Consultant of Tropical \\ Medicine and Fevers ${ }^{2}$, and Military Medical Academy, Cairo $11291^{3}$, Egypt \\ Abstract
}

The bloodsucking arthropod bite is the cofactor in the transmission of infectious diseases to man and animals. They release with saliva powerful anti-homeostatic and immuno-modulators that favor the replication and the establishment of the infective pathogen. The transmission depend on the close contact of the child with a seropositive mother (or relatives) whose infective saliva is used to relieve itching and scratching at the arthropod bite's sites. Vector-borne diseases are caused by parasites, bacteria or viruses transmitted by the hematophagous arthropods bite (mainly ticks and mosquitoes). The past decades there were emergence of new diseases or re-emergence of existing diseases, due to changes in their epidemiology (i.e. geographical distribution, prevalence, pathogenicity and vector-capacity). Besides, human factors, such as travel with pets, changes in human habitats, social and leisure activities have their input, but climate changes also have a direct impact on arthropod vectors. Vaccinations are up to date for diseases prevalent in the area, but what about diseases beyond vaccination? Wear light-colored, long-sleeved shirts and long trousers, tucked into socks or boots, and the use of insect repellent on exposed skin and clothing to protect from being bitten by mosquitoes, sandflies and/or ticks. This review discussed the vectors, diseases and feasible insecticidal control. Key words: Arthropod-borne infectious diseases, Bites, Repellant, Vector-control

\section{Introduction}

The approach to protection against arthropod bites is influenced by the level of protection that is needed in a specific situation. For example, a combination of chemicallytreated gear and clothing and a strong chemical repellent may be necessary in areas with high concentrations of disease-carrying arthropods. In contrast, milder repellents may be sufficient to prevent nuisance bites in areas with low levels of disease vectors (CDC, 2009). Arthropods form Phylum Euarthropoda, which includes insects, arachnids, myri apods, and crustaceans. Term Arthropoda as originally proposed refers to a proposed grouping of Euarthropods and the phylum Onychophora (Ortega-Hernández, 2016)

Repellents are variably useful in deterring mosquitoes, biting flies, fleas, midges, chiggers, and ticks. Repellents are not effective against stinging insects, such as Hymenoptera species (yellow-jackets, wasps, bees, hornets, imported fire ants, and harvester ants) or spiders (Abdel-Rahman et al, 2015). Unlike blood-sucking arthropods, stinging insects and spiders do not seek out humans to feed. They sting/bite man reflexively in selfdefense or to defend the nest (some hymenopterans) or egg sacs (some spiders), and it is not possible to chemically deter these extreme behaviors short of using an insecticide.

\section{Review and Discussion}

Permethrin-treated clothing: Permethrin is a synthetic compound that is not a repellent, but rather causes nervous system toxicity to insects. Its toxicity in humans is low. For the prevention of insect bites, permethrin is applied to clothing or bedding, but not to the skin. It is applied to the skin briefly in the treatment of head lice and scabies (Fradin, 1998). Permethrin is effective against mosquitoes, flies, ticks, and chiggers. Insects encountering permethrin-treated material either leave immediately or die if they remain in contact. For some situations, permethrin-treated clothing alone, without an additional repellent applied to skin proved sufficient protection (Brown and Hebert, 1997).

Permethrin is available as a spray for the treatment of clothing and gear (e.g., Sawyer ${ }^{\mathrm{TM}}$ Permethrin Clothing Insect Repellent, others). Fabrics should be sprayed on both 
sides for 30 to 45 seconds and allowed to a week, even after several washings (Schreck and McGovern, 1989).

Clothing and gear impregnated with permethrin (Insect Shield ${ }^{\mathrm{TM}}$ ) are also available. The United States (US) Environmental Protection Agency (EPA) has registered this technology and assigned the products a toxicity category IV (i.e., practically non-toxic, not an irritant). Products made with this material carry no warnings about use in children or pregnant women. These materials maintain their repellency through approximately 70 laundry cycles, according to the manufacturer (Gupta et al, 1989). A randomized study comparing at-home treated clothing, commercially treated clothing, and untreated ones showed that subjects wearing treated clothing were 3.36 times less likely to have nymphal Ixodes scapularis ticks attach to their body than subjects wearing untreated clothing. In addition, ticks that did attach to subjects with treated clothing were more likely to be dead within $2.5 \mathrm{hrs}$ of attachment (Miller et al, 2011).

The combination of permethrin-treated clothing and a DEET-based repellent on any exposed skin may provide the best protection available against insect bites. This combination is particularly important for people with regular exposure to biting arthropods, as not all species of mosquitoes worldwide are repelled by DEET, but all are deterred or killed by permethrin.

Experimentally, efficacy of 5\% permethrin lotion as a topical repellent has been investigated in comparison to a 50\% DEET spray against Aedes aegypti bites. Permethrin's repellency was significantly inferior to DEET (Miot et al, 2008).

Repellents: Among repellents for which a mechanism of action has been described, some act as agonists at olfactory receptors, binding the receptors and blocking recognition of suitable prey. Others antagonize olfactory receptors and actively reverse a normally attractive scent into a deterring scent. Due to highly divergent receptors, the same compound may act as an agonist in one species and an antagonist in another (Bohbot et al, 2011).

Proper application: Guidelines regarding safe and effective use of insect repellents in order to maximize effectiveness and minimize side effects were issued by the United States (US) Environmental Protection Agency (EPA). These are particularly important when using DEET-based repellents: 1- Use just enough repellent to lightly cover but not saturate the skin. 2- Repellents should be applied to exposed skin, clothing, or both, but not under clothing. 3- A thin layer can be applied to the face by dispensing repellent into the palms, rubbing hands together, and then applying to the face. 4- Repellent should be washed from the palms after application to prevent contact with the eyes, mouth, and genitals. 5- Do not use repellents over cuts, wounds, inflamed, irritated, or eczematous skin. 6- Do not inhale aerosols, spray them in enclosed spaces or near food, or get them into the eyes. 7- Do not apply insect repellent to the hands of small children, as it will inevitably be rubbed into the eyes. 8- Frequent reapplication of repellent is unnecessary, and 9- The areas treated with repellent should be washed with soap and water once the repellent was no longer needed (Bohbot and Dickens, 2010). But, the protection is shortened by swimming, washing, sweating, wiping, exercise, and rainfall.

Specific agents: The most effective insect repellents are: 1- DEET (N,N-diethyl-3-methyl benzamide), 2- Picaridin (KBR 3023), 3- PMD (P-methane-3,8-diol), 4- BioUD, \& 5- IR 3535 (Schofield et al, 2007). These agents are not equal in efficacy and provide varying degrees of protection against different arthropods.

1- DEET (N,N-diethyl-3-methylbenzamide) is effective against mosquitoes, biting flies, chiggers, fleas, and ticks. DEET has been in use for more than 50 years and is considered the "gold standard" of insect repellents (Pickett et al, 2008). No other compound covers as broad a spectrum of arthropods or offers 
the extended duration of action of DEET (Katz et al, 2008). In addition, there are microencapsulated formulations (e.g., 3 $\mathrm{M}^{\mathrm{TM}}$ Ultrathon $^{\mathrm{TM}}$ ), which increase the period of evaporation (and hence repellency) while reducing absorption by skin. These products have made it possible to decrease the concentration of DEET without sacrificing its duration of action (Kasting et al, 2008).

DEET is available in many products, in concentrations ranging from less than $10 \%$ to more than $75 \%$. The effectiveness of DEET plateaus at approximately $30 \%$, but higher concentrations provide longer duration of protection. Products with concentrations around $10 \%$ are effective for periods of approximately two hours; a concentration of about $24 \%$ provides an average of five hours of protection. Protection is shortened by swimming, washing, rainfall, sweating, and wiping (Fradin and Day, 2002). A prudent approach is to select the lowest concentration effective for the amount of time spent outdoors. Products with 10 to $35 \%$ DEET are adequate in most circumstances. Higher concentrations should be reserved for situations in which insect infestation is high, elevated temperatures and humidity may limit evaporation, or time outdoors exceed 3 to 4 hours.

Adverse effects: Although serious adverse reactions to DEET are uncommon, excessive absorption through the skin can cause dermatitis, allergic reactions, and rare neurotoxicity. DEET can damage some plastics, and clothes made from synthetic fibers such as spandex or rayon, and some patients dislike the oily and sticky skin sensation that DEET can cause. Repellents containing DEET may reduce the efficacy of sunscreens applied simultaneously, although labeling of the combined products containing both components should have taken this into account and the sunscreen component should provide the stated sun protection factor. These combination products are not recommended for use in children, as given by the CDC (1989).

Use in children: Used as directed, DEET may be safe for children older than two months of age. However, adverse neurologic effects, such as encephalopathy were reported with massive exposure and chronic use. Overall, fewer than 20 cases were reported worldwide and each developed in the setting of inappropriate use (oral ingestion or repeated exposure to high concentrations), with at least three fatalities. Hypersensitivity pneumonitis in a child following inhalation of a DEET-containing insect repellent was also reported (CDC, 1989). The American Academy of Pediatrics (AAP) agreed with the recommendation that children younger than two months of age should not use DEET products. For older infants and children, repellents with 10 to $30 \%$ DEET proved safe and effective when used according to the product labels directions (Koren et al, 2003).

Products containing both DEET and sunscreen are not recommended for children because reapplication (as may be necessary for sunscreen component) resulted in an excessive exposure to DEET. DEET-containing sunscreens should not be reapplied and must be washed off when back indoors or no longer needed (Briassoulis et al, 2001).

Use in pregnancy: The recommendations for DEET use in pregnant and lactating women do not differ from those for non-pregnant adults (Morton et al, 2006). The CDC has advised pregnant women to take precautions to reduce their risk of acquiring arboviral infections (e.g., West Nile Virus) by avoiding mosquito bites through use of protective clothing and DEET-based repellents (Garrettson, 1997). First trimester exposure of rats and rabbits to DEET did not cause an increased risk of malformations in offspring, although one study using a dose several-fold higher than normal human dose reported an increase in low birth weight (Schoenig et al, 1994). There are no human data for first trimester exposure. A double-blind, randomized, therapeutic trial of insect repellents for the prevention of malaria in 897 pregnant women did not find any adverse neurologic, gastrointestinal, or dermatologic effects in women who applied a median total DEET 
dose of $214 \mathrm{~g}$ per pregnancy (range $=0$ to $345 \mathrm{~g}$ ). No adverse effects were noted on fetal/infant survival, growth, or development up to one year of age. DEET was detected in four cord blood samples from a randomly selected subgroup of 50 DEET users (McGready et al, 2001).

2- Picaridin: Picaridin (KBR 3023), a plantderived piperidine compound, is effective against mosquitoes, ticks, and the sand fly Phlebotomus papatasi (Badolo et al, 2004). This agent has been successfully used for years in Europe and Australia. In the US, it is available in a $20 \%$ solution (Sawyer ${ }^{\mathrm{TM}}$ Insect Repellent), and in a 7 or $15 \%$ solution (as Cutter Advanced ${ }^{\mathrm{TM}} \&$ Cutter Advanced Sport $^{\mathrm{TM}}$, respectively). Picaridin higher concentrations (e.g., 20\%) gave similar efficacy to DEET when used for short periods (Costantini et al, 2004). But, DEET has a longer duration of action (Frances et al, 2004).

Field trials comparing efficacy of picaridin to DEET for protection against mosquitoes were performed with varying concentrations of picaridin; these trials have gave comparable potency between high strength picaridin and DEET up to about five hours after application (Preto- rius et al, 2003), For ticks (which are harder to repel) one study showed equivalent potency only for the first hour, after which DEET was superior. The manufacturer recommended application every three to four hours (Klun et al, 2006).

Adverse effects: No toxicity in humans was reported where it has been in long-term use, although hepatic toxicity has been reported in rats at very high doses (Wahle et al, 1999). Picaridin has an excellent tolerability profile, in contrast to DEET. Picaridin is odorless, non-sticky, and non-greasy; it also does not irritate skin, stain fabrics, or degrade plastics (Astroff et al, 2000).

3- PMD (P-menthane-3, 8-diol): PMD is the active ingredient in oil of lemon eucalyptus and in the most widely-used Chinese insect repellent, quelling. It is a plant-derived ingredient that has been listed by the Environmental Protection Agency (EPA) as effe- ctive against mosquitoes, gnats and biting flies (CDC, 2007a) In USA, PMD is available as 65\% PMD (Repel Lemon Eucalyptus Insect Repellent Lotion and Spray Lotion ${ }^{\mathrm{TM}}$ \& Survivor Lemon Eucalyptus Insect Repellent ${ }^{\mathrm{TM}}$ ) and 10\% PMD (Off! Botanical Insect Repellent ${ }^{\mathrm{TM}}$ ). Efficacy studies are limited. Generally, PMD is approximately one-half as effective as DEET, such that a 30\%PMD product would protect as well as a $15 \%$ DEET product (Carroll and Loye, 2006a). As an example, one comparative trial of $40 \%$ PMD and $25 \%$ DEET gave a mean protection time of 3.8hours with PMD compared with 5.6hours with DEET (Frost, 2005)

Adverse effects: Toxicity in animal studies was limited to eye irritation, with one study reporting skin irritation in a human subject. However, neither problem is common. The CDC recommends avoiding eye contact and not using PMD on the faces and hands of small children (Barnard et al, 2002)

Use in children: The compound has not been adequately tested in children younger than three years old and should not be used in this group.

4- BioUD: BioUD is a tomato-derived arthropod repellent registered by the US EPA in April 2007, and assigned the lowest toxicity rating. Its active ingredient is $7.75 \%$-undecanone. BioUD is available in USA as BiteBlocker $^{\mathrm{TM}}$ (Witting-Bissinger et al, 2008). BioUD was found to repel mosquitooes similarly to products with up to $30 \%$ DEET in one report. A study cited on the manufacturer's website indicated that Bio UD was comparable to 7\% DEET. Very hi-gh concentrations of BioUD and DEET have similar repellency against ixodid ticks, but this cannot necessarily be extrapolated to the lower concentrations intended for human use (Bissinger et al, 2009)

5- IR 3535: IR 3535 is a synthetic repellent available in the United States as Avon SkinSo-Soft Bug Guard plus IR 3535 Expedition $^{\mathrm{TM}}$. There are limited studies comparing IR 3535 to DEET or picaridin. It appeared to be the least effective of the three in one 
study, although it compared favorably with DEET in another. One study indicated a long duration of action (Cilek et al, 2004)

Less effective and ineffective agents: Other agents marketed as insect repellents include citronella, and various botanical oils, vitamin supplements, and the herbal preparations. There are also a variety of electronic devices and repellent-impregnated wristbands available.

- Citronella: Citronella is a plant-based repellent that lacks the broad spectrum of activity and duration of action of DEET (Carroll, 2008). Frequent application may compensate for its limited duration of effectiveness, although animal studies have shown citronella-based repellents to be potential dermal sensitizers. Citronella probably is not effective in repelling ticks.

- $\quad$ Botanical oils: Various botanical oils, including sandalwood, geranium, soybean, and others, have been used alone or in combination for repelling mosquitoes. The majority of these botanical oils and botanical-based repellents showed that the protection offered by them was far inferior to DEET, PMD, or picaridin (Girgenti and Suss, 2002).

Ingestion of strong-smelling foods or other substances: Claims that ingestion of odiferous substances, such as garlic, onions, cruciferous vegetables or mineral sulfur, can repel biting insects have not been substantiated (Ritchie et al, 2006).

Vitamin supplements and herbal remedies: No controlled scientific study of ingested vita-min or herbal remedies has ever shown these interventions to protect users from biting insects (Day, 2009)

Electronic devices: The electronic mosquito repellents are devices that emit highpitched sounds that are generally inaudible to the human ear. A Cochrane review of ten field studies concluded there was no evidence that the devices repelled the mosquitoes to any degree. Wristbands impregnated with insect repellents are not effective, regardless of the repellent used (Enayati et al, 2007).

Protection against specific insect-vectors:
Mosquitoes: Diseases transmitted by mosquitoes: a- Protozoa: The female Anopheles spp. carries five different species of zoonotic protozoa cause malaria. Worldwide, malaria is the leading cause of premature mortality, particularly in children under the age of five, with about 207 million cases and more than half a million deaths in 2012, death toll increased to one million as of 2018 according to the American Mosquito Control Association, b-Myiasis: human botfly Dermatobia hominis attaches its eggs to the underside of a mosquito, as intermediate vector agents and when the mosquito takes a blood meal from a human or an animal, the body heat of mammalian host induces larval hatching, c- Helminthiasis filariasis (elephantiasis) about 40 million people are living with a filariasis disability, d- Virus: Yellow Fever, Dengue Fever, Zika Fever and Chikungunya Fever are transmitted mostly by Aedes aegypti. Other viral diseases as epidemic polyarthritis, Rift Valley fever, Ross River fever (Aly et al, 2019), St. Louis encephalitis, West Nile fever, Japanese encephalitis, La Crosse encephalitis and several other encephalitic diseases are carried by several different mosquitoes. Eastern equine encephalitis (EEE) and Western equine encephalitis (WEE) occur in the United States where they cause diseases in man, horses, and some bird species. Because of the high mortality rate, EEE \& WEE is regarded as two of the most serious mosquito-borne diseases in the United States. Symptoms range from the mild flu-like illness to encephalitis, coma and death (CDC, 2019a), e- Myxomatosis is spread by the biting insects, including mosquitoes (Kerr, 2013), and f- A mosquito's anti-coagulants with initial bite no reaction but with subsequent bites the body's immune system develops antibodies and a bite becomes inflamed and itchy within 24 hours. Some adults can become desensitized to mosquitoes and have little or no reaction to their bites, while others (mainly young children) can become hyper-sensitive with bites causing blistering, bruising, and large inflamma- 
tory reactions, a response known as skeeter syndrome (Abdel-Motagaly et al, 2017). All viruses carried by arthropods (as mosquitoes or ticks) are collectively known as arboviruses (CDC, 2007b). Other species of Aedes, Culex and Culiseta are also involved in diseases transmission.

The most effective protection against mosquitoes consists of permethrin-treated clothing and gear, combined with DEET or picaridin applied to exposed skin. DEET was preferable for longer periods of exposure $(\mathrm{Ku}-$ ehn, 2005). But, in areas with fewer mosquitoes and low risk of disease transmission, just one of these measures alone may be sufficient. Alternative repellents, such as PMD, BioUD, and IR 3535, may also be adequate in lower risk environments, although these agents have not been as thoroughly studied.

2- Ticks: Main diseases they transmit: aBacteria: 1- Lyme disease or Borreliosis, 2Relapsing fever (tick-borne relapsing fever, different from Lyme disease due to different Borrelia species), 3- Typhus several diseases caused by Rickettsia bacteria, 4- Rocky Mountain spotted fever, 5- Helvetica spotted fever, 6- Human granulocytic anaplasmosis (formerly human granulocytic ehrlichiosis, 7- Bartonellosis, 8-Tularemia, b- Viral: 9-Tick-borne meningoencephalitis, 10- Powassan virus/deer tick virus' 11 - Colorado tick fever, 12- Crimean Congo hemorrhagic fever, 13- Severe febrile illness, c- Protozoan: 14Babesiosis, 15- Cytauxzoonosis, 16- Theileriases, d- Toxin: 17- Tick paralysis, and 18- Allergies (CDC, 2019b)

The best protection against ticks consists of permethrin-treated clothing and gear, combined with DEET applied to exposed skin. Even DEET, which is considered the most effective agent, only repels ticks for short periods of time. Wearing clothing properly should keep ticks from gaining access to the skin (pant legs tucked into socks...etc.), and light-colored materials are preferable, as ticks are more easily seen against these. Visual inspection of man's skin after any time spent outdoors is critical for effective prevention of tick-borne disease.

Personal protection: Several strategies for personal protection included: 1- Checking for and removing ticks after outdoor activities. 2- Wearing protective clothing. 3- Using tick repellent on skin and clothing. 4- Avoiding areas where ticks are abundant (Hayes and Piesman, 2003).

Ticks that are found already attached to the skin should be removed promptly. Tick size and appearance can be helpful clues for determining the disease transmission risk, but the validity of this information is highly dependent upon the expertise of the person viewing the tick. Patients sometimes confuse tick bites with bites by other types of arthropods. As an example, in a study $6 \%$ of specimens submitted by clinicians for tick identification were actually arthropods (commonly beetles and lice) rather than ticks (Falco et al, 1998).

Prophylaxis guidelines: Infectious Diseases Society of America (IDSA) guidelines recommended the antibiotic prophylaxis only in the patients who meet ALL of the following criteria: a- Attached tick identified as an adult or nymphal Ixodes scapularis tick (deer tick), b- Tick is estimated to attach for $\geq 36$ hours, c- Prophylaxis is begun within $72 \mathrm{hrs}$ of tick removal Local rate of infection of ticks with $B$. burgdorferi is $\geq 20 \%$, and eDoxycycline is indicated (i.e., patient not $<8$ years of age, pregnant, or lactating). If the patient meets all of these criteria, the recommended dose of doxycycline is $200 \mathrm{mg}$ for adults and $4 \mathrm{mg} / \mathrm{kg}$ up to a maximum dose of $200 \mathrm{mg}$ in children $\geq 8$ years, given as a single dose. It is important to note that this regimen has never been tested in children; this recommendation is extrapolated from the experience in adults. If the patient cannot take doxycycline, the IDSA does not recommend prophylaxis with an alternate antibiotic for the following reasons: there are no data to support the efficacy of a short course of another antibiotic; longer courses of antibiotics may lead to adverse effects; standard antibiotic treatment is highly effective if the 
Lyme disease actually occurs; and finally, the risk of developing a serious complication of Lyme disease after a recognized tick bite is extremely low (Wormser et al, 2006). It should be remembered that Lyme disease less often results from a recognized tick bite, since removal of tick within two to three days of attachment usually prevents transmission of B. burgdorferi. More commonly, Lyme disease is transmitted by the unrecognized tick that feeds to repletion (about four to five days) and then falls off without the person knowing that he or she has been bitten (El-Bahnasawy et al, 2015). Tick removal: Several methods of tick removal have been advocated. A study that evaluated the use of forceps or protected fingers, or the application of petroleum jelly, fingernail polish, isopropyl alcohol, or a hot match, found that only the use of forceps or protected fingers resulted in the satisfactory removal of 29 adult American dog ticks without leaving the mouthparts in the host skin (Needham, 1985). The proper technique for removal of the attached tick includes the following steps: If available, use tweezers or small forceps to grasp the tick as close to the skin surface as possible. In the absence of tweezers, one can use paper or cloth to protect the fingers during tick extraction (Nadelman et al, 2001). Pull straight up gently but firmly, using steady pressure. Do not jerk or twist. Do not squeeze, crush, or puncture the body of tick, since its fluids may contain infectious agents. Disinfect the skin thoroughly after removing the tick and wash hands with soap and water. If sections of the tick mouthparts remain in the skin, they should be left alone as they will normally be expelled spontaneously. After the tick removal and the skin cleansing, the person bitten (or the parents) should observe the area for the development of erythema migrans (EM) for up to 30 days following exposure. Components of tick saliva can cause transient erythema that should not be confused with EM. Since the tick usually needs to be attached for two to three days before transmission of Lyme disease agent occurs, tick removal within this time frame often prevents the infection (Sood et al, 1997). As to Lyme disease, Adham et al. (2010) in Egypt by PCR High infection rate $(66 \%)$ of B. burgdorferi s.l. was detected in both nymph and adult soft ticks Ornithodoros savignyi. Elhelw et al. (2014) detected outer surface protein A gene of B. burgdorferi by PCR and anti-B. burgdorferi IgM by ELISA in human contacts who were suffering from fever of unknown origin, confirmed the emerging of such neglected zoonotic Lyme diseases in Egypt.

3- Other insects: A- Biting flies: 1- Chrysops species transmit filarial Loa loa among humans (El-Bahnasawy et al, 2016) and Tabanidae with 30 species identified in Egypt (Steyskal and El-Bialy, 1967), vectors of some blood-borne-bacterial, viral, protozoan and worm diseases of mammals, as equine infectious anemia virus and various Trypanosoma species that infect animals and humans, zoonotic T. evansi was recorded in Egypt (Haridy et al, 2011). Stomoxys calcitrans, cattle heavily infested with stable flies become anemic and milking cows with lower milk production (Catangui et al, 1997). The stable fly bites man at rest in the outdoors. It was incriminated as a vector of $T$. evansi, $T$. bruce $i$, brucellosis, equine infectious anemia, African horse sickness, and fowl-pox (Janovy and Roberts, 2000). 2- S. calcitra$n s$ reported as a vector of Bacillus anthracis, the causative agent of anthrax (Mongoh et al, 2008). 3- Simulium or black flies, one species recorded in Egypt (Steyskal and ElBialy, 1967). Onchocerciasis is transmitted in limited areas of Tropical Africa (sub-Saharan Africa, particularly in Nigeria and Zaire), Yemen, Saudi Arabia and (Helmy and Al Mathal, 2003), Latin America; with man the only definitive host for $O$. volvulus. Other onchocercal species that infect animals as $O$. gibsoni was reported in Egypt in imported cattle from Sudan. 4- Culicoides Egyptian species were 46 (Morsy et al, 1999). Many species are vectors of Mansonella infections (M. ozzardi, M. perstans, M. streptoce- 
rca), Onchocerca gibsoni and $O$. cervicalis, Leucocytozoon, Plasmodium agamae, Bluetongue virus, Schmallen berg virus, African horse sickness, bovine ephemeral fever $(C$. osystoma \& $C$. nipponesis), Akabane virus, Queensland itch and epizootic hemorrhagic fever (Purse et al, 2015).

5- Sandflies only female are responsible for biting and sucking blood of mammals, reptiles and birds; blood protein is necessary for the production of eggs, making it an autogenous reproducer. Phlebotominae are the main vectors of all leishmaniases and pappataci fever; both are confusingly referred to as sandfly fever. But, in the New World, leishmaniasis is spread by sand flies of the genus Lutzomyia; in the Old World, the disease is spread by sandflies of genus Phlebotomus (CDC, 2011). In Egypt, 12 Phlebotomus species were recorded mainly in Sinai Peninsula (Saleh et al, 2015). Zoonotic cutaneous leishmaniasis transmitted by $P h$. papatasii was reported in some Egyptian Governorates but mainly in Northern Sinai Governorate (Morsy, 1996). Besides, Shehata et al. (2009) reported the first Leishmania tropica isolation from ACL human cases in a Northe rn Sinai Community bordering Palestine. $L$. tropica patients had not traveled from the region in over a year, suggesting these cases are autochthonous. Moreover, Morsy (2013) declared ted that the zoonotic and anthroponotic cutaneous leishmaniasis predisposed to human skin cancer and gave a critical local and regional review of cases. Infantile visceral leishmaniasis transmitted by the $\mathrm{Li}$ byan introduced $P$. langeroni to West of Alexandria, mainly Al Agamy District (Morsy, 1997). Also, El Bahnasawy et al. (2013) detected $P$. langeroni the vector of IVL in the northern coastal zone, and suggested that the disease could reinvade or reemerge in Egypt. Sandfly species locate humans and other animals by sensing certain substances, including carbon dioxide and moisture in exhaled breath, dark colors and movement, warmth and perspiration. Once a suitable host is located, a fly inserts its piercing mou- thparts, lacerates skin, and injects its anticoagulant-containing saliva to keep blood flowing (Morsy et al, 1992). Over-the-counter repellents with high DEET or picaridin concentrations are proven to work, but may not be suitable for some people, e.g. people with sensitivity and pregnant women. The effectiveness of DEET and picaridin products differed among individuals as some people reporting better results with one product over another, but other people finding neither product effective for them and Lemon Eucalyptus juice (not essential oil) showed to be as effective as the DEET (Morsy et al, 1993; Carroll and Loye, 2006b). 6- Chiggers is the common name for species of the Trombiculid family of mites. Bites from these larva cause local pruritus and irritation, formally known as trombiculiasis or trombiculosis, and 7- Fleas are highly specialized bloodsucking ecto-parasites of family Siphonaptera or the wingless siphon. They have a formidable reputation of claiming more victims than all the wars ever fought, as a result of the "bubonic" (Black Death) plague they spread throughout the world in the $14^{\text {th }}$ Century causing the deaths of over 200 million people. The ancient Egyptians were plagued by all sorts of parasites and vermin, of which the Bible mentions a few (just an aside: J. D. Blaidell in his 'The curse of the pharaohs' sees the ten plagues as symptoms of an anthrax epidemic, others connect them with the explosion of the volcano on Santorini). Fleas are better known for their irritation and pest status worldwide (El Bahnasawy et al, 2012).

Fleas are widely spread on all continents, including Antarctica. They occur on host and in their nests in all types of habitats from the equatorial deserts and tropical rainforests to the northern most regions of Arctic tundra (Hoogstraal, 1965). In Egypt, so many authors dealt with fleas' types, medical and veterinary importance (El Okbi et al, 1991) and flea-index in all Egyptian Governorates particularly the border ones (Mikhail et al, 2011). 
It's normal to hear that neighbor's dog has fleas, but it's pretty embarrassing to tell one that you or your kids are a walking flea hotel. Even if people keep quiet about it, flea bites on humans are all too common because people live in such close proximity with their pets. Fleas should be attacked as quickly as possible, hitting both the source and premises. If a skin reaction to flea bites occurs, consult a physician (Morsy, 2012).

The control of biting insects is deterred by DEET in many insect repellents. It's a manmade chemical and is proven to deter insects as mosquitoes, blackflies, ticks, fleas, chiggers and no-see-ums. Repelling these insects means a significant decrease in your chances of contracting malaria, West Nile virus, Lyme disease and many other insect-borne illnesses (Xu et al, 2019). PMD is the only plant-based repellent that has been advocated for use in disease endemic areas by the CDC (2010), due to its proven clinical efficacy to prevent malaria and pose no risk to man (Maia and Moore, 2011). DEET and picaridin exert repellent and deterrent effects on sand fly (Alzogaray et al, 2000).

\section{Conclusion and Recommendations}

Dry-lands among the biosphere's most naturally limiting and environmentally variable ecosystems constitute the majority of the African continent. The environmental sustainable and human development along with the vector-borne infectious diseases control historically especially in Africa.

For most patients requiring an insect repellent DEET was suggested (Grade 2B). The product containing 10 to $35 \%$ DEET is adequate in most circumstances, with higher concentrations reserved for situations in which insect infestation is high, the repellent may be partially washed off, or time outdoors will exceed three to four hours. Microencapsulated formulations are preferred, as these protect longer with the lower concentrations of active repellent. DEET must be used carefully as directed, can use safely by pregnant women and applied once daily to children older than two months and more. Picaridin
$20 \%$ is a reasonable alternative for people to avoid the unpleasant characters of DEET and are willing to accept a somewhat shorter acting repellent. Less studied repellents include PMD, BioUD, and IR 3535. Available studies suggest these are less effective than DEET or picaridin, but they may be adequate in low-risk situations. The approach to preventing arthropod bites depends upon the level of protection that is needed.

For environments in which there is a high concentration of biting arthropods and/or a disease transmission risk, the combination of permethrin-treated clothing and gear and a DEET-based repellent applied to any uncovered skin is recommended (Grade 1B). For protection from ticks, it is also important to keep them from crawling under clothing and to inspect one's skin regularly. For environments where there are lower concentrations of insects and less disease risk, one of these measures (i.e., permethrin treated clothing or a repellent) may be sufficient.

\section{References}

Abdel-Motagaly, AME, Mohamad, HM, Morsy, TA, 2017: A mini-review on skeeter syndrome or large local allergy to mosquito bites. J. Egypt. Soc. Parasitol. 47, 2:415-24.

Abdel-Rahman, RZ, Mohamad, HM, Morsy, ATA, Morsy, TA, 2015: Allergic reactions caused by venom of hymenopterous stinging insects and the role of health care workers. J. Egypt. Soc. Parasitol. 45, 2:403-12

Adham, FK, Abd-El-Samie, EM, Gabre, RM, El Hussein, H, 2010: Detection of tick blood parasites in Egypt using PCR assay II- Borrelia burgdorferi sensu lato. J. Egypt. Soc. Parasitol. 40, 3:553-64.

Aly, NZ, Shoukry, NM, Morsy, TA, 2019: Ross River Virus is a mosquito-transmitted alph avirus: Is it threatened to Arab Countries including Egypt? J. Egypt. Soc. Parasitol. 49, 3:54350 .

Alzogaray, RA, Fontan, A, Zerba, EN, 2000: Repellency of DEET to nymphs of Triatoma infestans. Med. Vet. Entomol. 14:6-11.

Astroff, AB, Young, AD, Holzum, B, et al, 2000: Conduct and interpretation of a dermal developmental toxicity study with KBR 3023 (a prospective insect repellent) in the Sprague-Da- 
wley rat and Himalayan rabbit. Teratology 61: 222-30.

Badolo, A, Ilboudo-Sanogo, E, Ouédraogo, A P, Costantini, C, 2004: Evaluation of the sensitivity of Aedes aegypti and Anopheles gambiae complex mosquitoes to 2 insect repellents: Deet and KBR 3023. Trop. Med. Int. Hlth. 9:330-9.

Barnard, DR, Bernier, UR, Posey, KH, Xue, RD, 2002: Repellency of IR3535, KBR3023, para-menthane-3,8-diol, and DEET to black salt marsh mosquitoes (Diptera: Culicidae) in the Everglades National Park. J. Med. Entomol. 39: 895-8.

Bissinger, BW, Apperson, CS, Sonenshine, D E, et al, 2009: Efficacy of the new repellent Bio UD against three species of ixodid ticks. Exp. Appl. Acarol. 48:239-42.

Bohbot, JD, Dickens, JC, 2010: Insect repellents: Modulators of mosquito odorant receptor activity. PLoS One 5:e12138.

Bohbot, JD, Fu, L, LE, TC, et al, 2011: Multiple activities of insect repellents on odorant receptors in mosquitoes. Med. Vet. Entomol. 25: 436-41.

Briassoulis, G, Narlioglou, M, Hatzis, T, 2001: Toxic encephalopathy associated with use of DEET insect repellents: A case analysis of its toxicity in children. Hum. Exp. Toxicol. 20:812.

Brown, M, Hebert, AA, 1997: Insect repellents: An overview. J. Am. Acad. Dermatol. 36, 2:243-9.

Carroll, SP, 2008: Prolonged efficacy of IR35 35 repellents against mosquitoes and black-legged ticks in North America. J. Med. Entomol. 45:706-12.

Carroll, SP, Loye, J, 2006: PMD, a registered botanical mosquito repellent with DEET-like efficacy. J. Am. Mosq. Control Assoc. 22:50712.

Carroll, SP, Loye, J, 2006b: Field test of a lemon Eucalyptus repellent against Leptoconops biting midges. J. Am. Mosq. Cont. Assoc. 22, 3: 483-5.

Catangui, MA, Campbell, JB, Thomas, GD, Boxler, DJ, 1997: Calculating economic injury levels for stable flies (Diptera: Muscida) on feeding heifers. J. Econ. Entomol. 90, 1:6-10.

CDC, 1989: Seizures temporally associated with use of DEET insect repellent-New York and Connecticut. MMWR Morb. Mortal. Wkly. Rep. 38:678-82.
CDC, 2007a: U.S. Environmental Protection Agency: p-Menthane-3,8-diol (011550) Fact Sheet.www.epa.gov/oppbppd1/biopesticides/ingred ients/factsheets/factsheet_011550.htm

CDC, 2007b: Information on arboviral encephalitides: Archived from the original on January 27 CDC, 2009: Updated information regarding mosquito repellents. www.cdc.gov/travel/yellowBo ok/Ch2-InsectsArthropods.aspx.

CDC, 2010: Protection against mosquitoes, ticks and other insects and arthropods.

CDC, 2011: West Nile Virus: Updated Insect Repellent. Cdc.gov, USA (2009-10-13).

CDC, 2019a: Mosquito-Borne Diseases, Infectious Disease Information, NCID.

CDC, 2019b: Trends in Tick-Borne Diseases.

Cilek, JE, Petersen, JL, Hallmon, CE, 2004: Comparative efficacy of IR3535 and DEET as repellents against adult Aedes aegypti \& Culex quinquefasciatus. J. Am. Mosq. Cont. Assoc. 20: 299-302.

Costantini, C, Badolo, A, Ilboudo-Sanogo, E, 2004: Field evaluation of the efficacy and persistence of insect repellents DEET, IR3535, and KBR 3023 against Anopheles gambiae complex and other Afrotropical vector mosquitoes. Trans. R. Soc. Trop. Med. Hyg. 98:644-52.

Day, J, 2009: Repellent wars. file://entomology. ifas.ufl.edu/pestalert/arbovirus/repellentwars.pdf El-Bahnasawy, MM, Ahmad, GMS, AbdelFattah, MA, Gaber, WAI, Morsy, TA, 2012: Is plague a problem in the Egyptians returning back from Libya? J. Egypt. Soc. Parasitol. 42, 2:329-48.

El-Bahnasawy, MM, Ahmed, GMS, Gaber, WAI, Morsy, TA, 2013: The infantile visceral leishmaniasis: Could it attack Egyptian North Coastal Region Again? J. Egypt. Soc. Parasitol. 43, 3:601-8

El-Bahnasawy, MM, Morsy, ATA, Ragab, IF, Khater, MKhA, Morsy, TA, 2015: Lyme disease: What heath care staff must know? Egyptian Military Medical Journal (EMMJ) 70, 2:40-50. El-Bahnasawy, MM, Morsy, ATA, El-Agroudi, MAM, Morsy, TA, 2016: Overview on the insect-borne loiasis. EMMJ 71, 1:46-60.

Elhelw, RA, El-Enbaawy, M, Samir, A, 2014: Lyme borreliosis: a neglected zoonosis in Egypt. Acta Trop. 140:188-92

El Okbi, LMA, Morsy, TA, El Shayeb, FA, Salama, MMI, Abo Gamrah, MMM, 1991: Fl- 
eas as an allergen in Egyptian asthmatic patients. J. Egypt. Soc. Parasitol. 21, 3:641-55.

Enayati, AA, Hemingway, J, Garner, P, 2007: Electronic mosquito repellents for preventing mosquito-bites and malaria infection. Cochrane Database Syst. Rev.:CD005434.

Falco, RC, Fish, D, D'Amico, V, 1998: Accuracy of tick identification in a Lyme disease endemic area. JAMA 280:602-9.

Fradin, MS, 1998: Mosquitoes and mosquito repellents: A clinician's guide. Ann. Intern. Med. 128:931-6.

Fradin, MS, Day, JF, 2002: Comparative efficacy of insect repellents against mosquito bites. N. Engl. J. Med. 347:13-8.

Frances, SP, Waterson, DG, Beebe, NW, Cooper, RD, 2004: Field evaluation of repellent formulations containing DEET and picaridin against mosquitoes in Northern Territory, Australia. J. Med. Entomol. 41:414-8.

Frost, AC, 2005: Oil of lemon eucalyptus as an insect repellent. Alt. Med. Alert. 8:85-9.

Garrettson, L, 1997: Commentary-DEET: Caution for children still needed. J. Toxicol. Clin. Toxicol. 35:443-9.

Girgenti, P, Suss, L, 2002: Repellent activity against Aedes aegypti (L.) of formulas based on natural vegetable extracts or synthetic active agents. Ann. Ig. 14:205-9.

Gupta, RK, Rutledge, LC, Reifenrath, WG, et al, 1989: Effects of weathering on fabrics treated with permethrin for protection against mosquitoes. J. Am. Mosq. Control Assoc. 5:176-82.

Haridy, FM, El-Metwally, MT, Khalil, HHM, Morsy, TA, 2011: Trypanosoma evansi in dromedary camel: With a case report of zoonosis in Greater Cairo, Egypt. J. Egypt. Soc. Parasitol. 41, 1:65-76.

Hayes, E, Piesman, J, 2003: How can we prevent Lyme disease?. N. Engl. J. Med. 348:2424-9.

Helmy, MM, Al Mathal, IM, 2003: Human in fection with Onchocerca volvulus in Asir District (Saudi Arabia). J. Egypt. Soc. Parasitol. 33, 2:385-90.

Hoogstraal, H, 1965: The flea (Siphonaptera) of Egypt: Host-parasite relationships of cricetid rodents (Family Spalacidae, Muridae, Gliridae, Dipodidae and Hystricidae). J. Egypt. Pub. Hlth. Assoc. 41: 343-79.

Janovy, J, Roberts, L, 2000: Foundations of Parasitology ( $6^{\text {th }}$ Ed.). USA: The McGraw-Hill Companies, Inc.

Kasting, GB, Bhatt, VD, Speaker, TJ, 2008:
Microencapsulation decreases the skin absorption of N,N-diethyl-m-toluamide (DEET). Toxicol. In-vitro 22:548-54.

Katz, TM, Miller, JH, Hebert, AA, 2008: Insect repellents: historical perspectives and new developments. J. Am. Acad. Dermatol. 58:86572 .

Kerr, P, 2013: Viral infections of rabbits: Veterinary clinics of North America: Exot. Anim. Pract. 16, 2:437-68.

Klun, JA, Khrimian, A, Debboun, M, 2006: Repellent and deterrent effects of SS220, Picaridin, and DEET suppress human blood feeding by Aedes aegypti, Anopheles stephensi and Phlebotomus papatasi. J. Med. Entomol. 43:34-9.

Koren, G, Matsui, D, Bailey, B, 2003: DEETbased insect repellents: safety implications for children and pregnant and lactating women. CMAJ 169:209-12.

Kuehn, BM, 2005: CDC: new repellents for West Nile fight. JAMA 293:2583-9.

Maia, MF, Moore, SJ, 2011: Plant-based insect repellents: a review of their efficacy, development and testing. Malar. J. 10, 1:S11. Doi: 10.

1186/1475-2875-10-S1-S1 1

McGready, R, Hamilton, KA, Simpson, JA, et al, 2001: Safety of the insect repellent N, N-diethyl-m-toluamide (DEET) in pregnancy. Am. J. Trop. Med. Hyg. 65:285-90.

Mikhail, MW, Soliman, MI, Morsy, TA, 2011: The current status of fleas according to environmental changes in some governorates in Egypt. J. Egypt. Soc. Parasitol. 41, 1:199-213.

Miller, NJ, Rainone, EE, Dyer, MC, et al, 2011: Tick bites protection with permethrintreated summer-weight clothing. J. Med. Entomol. 48:327-32.

Miot, HA, Ferreira, DP, Mendes, FG, et al, 2008: Efficacy of topical permethrin as repellent against Aedes aegypti's bites. Dermatol. Online J. 14:1-8.

Mongoh, MN, Dyer, NW, Stoltenow, CL, Khaitsa, ML, 2008: Risk factors associated with anthrax outbreak in animals in North Dakota, 2005: A retrospective case-control study. Publ. Hlth. Repots. 123, 3:352-9.

Morsy, TA, 1996: Cutaneous leishmaniasis in Egypt: Review and comment. J. Egypt. Soc. Parasitol. 26, 1:105-30.

Morsy, TA, 1997: Visceral leishmaniasis with special reference to Egypt (Review and comment). J. Egypt. Soc. Parasitol. 27, 2:373-96. Morsy, TA, 2012: Insect bites and what is eati- 
ng you? J. Egypt. Soc. Parasitol. 42, 2:291-308. Morsy, TA, 2013: Cutaneous leishmaniasis predisposing to human skin cancer: Forty years local and regional studies. J. Egypt. Soc. Parasitol. 43, 3:629-48.

Morsy, TA, Fayad, ME, Younis, TA, 1999: Culicoides bedfordi Ingram and Macfie, a new record in Egypt. J. Egypt. Soc. Parasitol. 19, 2: 413-6.

Morsy, TA, Merdan, AI, Shoukry, A, El Said, S, Wahba, MM, 1992: Experimental efficiency of Phlebotomus papatasi in maintaining development of four species of Leishmania. J. Egypt. Soc. Parasitol.22, 1:241-51.

Morsy, TA, Aboul Ela, RGh, El Gozamy, BM R, Salama, MMI, Ragheb, DA, 1993: Residual effect of four insecticides applied for indoor control of Phlebotomus papatasi (Scopoli). J. Egypt. Soc. Parasitol. 23, 2:485-92.

Morton, R, Brooks, M, Eid, N, 2006: Hypersensitivity pneumonitis in a child associated with direct inhalation exposure of an insect repellent containing DEET. Pediatr. Asthma Aller. Immunol. 19:44-9.

Nadelman, RB, Nowakowski, J, Fish, D, et al, 2001: Prophylaxis with single-dose doxycycline for the prevention of Lyme disease after an Ixodes scapularis tick bite. N. Engl. J. Med. 345: 79-82.

Needham, GR, 1985: Evaluation of five popular methods for tick removal. Pediatrics 75:9971002.

Ortega-Hernández, J, 2016: Making sense of 'lower' and 'upper' stem-group Euarthropoda, with comments on the strict use of the name Arthropoda von Siebold, 1848. Biol. Rev. Camb. Philos. Soc. 91:255-73.

Pickett, JA, Birkett, MA, Logan, JG, 2008: DEET repels ORNery mosquitoes. PNAS 105: 36-40.

Pretorius, AM, Jensenius, M, Clarke, F, Ringertz, SH, 2003: Repellent efficacy of DEET and KBR 3023 against Amblyomma hebraeum (Acari: Ixodidae). J. Med. Entomol. 40:245-51. Purse, BV, Carpenter, S, Venter, GJ, Bellis, G, Mullens, BA, 2015: Bionomics of temperate and tropical Culicoides midges: Knowledge gaps and consequences for transmission of Culicoides-Borne Viruses. Ann. Rev. Entomol. 60, 1: 373-92.

Ritchie, SA, Williams, CR, Montgomery, BL, 2006: Field evaluation of New Mountain Sandal-wood mosquito sticks and New Mountain
Sandalwood botanical repellent against mosquitoes in North Queensland, Australia. J. Am. Mosq. Control Assoc. 22:158-62.

Saleh, AMA, Labib, NA, Abdel-Fattah, MS, Al-Attar, MBF, Morsy, TA, 2015: Sand-fly Phlebotomus papatasi (Phlebotominae): A general review with special reference to zoonotic cutaneous leishmaniasis in Egypt. J. Egypt. Soc. Parasitol. 45, 3:525-44.

Schoenig, GP, Neeper-Bradley, TL, Fisher, L C, Hartnagel, RE Jr, 1994: Teratologic evaluations of N,N-diethyl-m-toluamide (DEET) in rats and rabbits. Fundam. Appl. Toxicol. 23:63-70. Schofield, S, Tepper, M, Gadawski, R, 2007: Laboratory and field evaluation of the impact of exercise on performance of regular and polymerbased DEET repellents. Vector Control 44:6-12. Schreck, CE, McGovern, TP, 1989: Repellents and other personal protection strategies against Aedes albopictus. J. Am. Mosq. Control Assoc. 5:247-52.

Shehata, MG, Samy, AM, Doha, SA, Fahmy, AR, Kaldas, RM, et al, 2009: First report of $L e$ ishmania tropica from a classical focus of $L$. major in North-Sinai, Egypt. Am. J. Trop. Med. Hyg. 81, 2:213-8.

Sood, SK, Salzman, MB, Johnson, BJ, et al, 1997: Duration of tick attachment as a predictor of the risk of Lyme disease in which Lyme disease is endemic. J. Infect. Dis.175:996-1002.

Steyskal, G, El-Bialy, S, 1967: A List of Egyptian Diptera with a bibliography and key to Families. Tech. Bull. No. 3: Ministry of Agriculture. Wahle, BS, Sangha, GK, Lake, SG, et al, 1999: Chronic toxicity and carcinogenicity testing in the Sprague-Dawley Rat of a prospective insect repellant (KBR 3023) using the dermal route of exposure. Toxicology 142:41-8.

Witting-Bissinger, BE, Stumpf, CF, Donohue, KV, et al, 2008: Novel arthropod repellent, Bio $\mathrm{UD}$, is an efficacious alternative to DEET. J. Med. Entomol. 45:891-8.

Wormser, GP, Dattwyler, RJ, Shapiro, ED, et al, 2006: The clinical assessment, treatment, and prevention of Lyme disease, human granulocytic anaplasmosis, and babesiosis: Clinical Practice Guidelines by the Infectious Diseases Society of America. Clin. Infect. Dis. 43:1089-94.

Xu, P, Zeng, F, Bedoukian, R, Leal, W, 2019: DEET and other repellents are inhibitors of mosquito odorant receptors for oviposition attractants. Insect Biochem. Mol. Biol. 113.103224.doi: 10.1016/j.ibmb.2019.10322. 